\title{
PROVING IT: EXPERIENCES OF SEXUAL MINORITIES IN THE CANADIAN REFUGEE DETERMINATION SYSTEM
}

by

Casey Anderson, BA, Trent University, 2009

\begin{abstract}
A Major Research Paper presented to Ryerson University
in partial fulfillment of the requirements for the degree of

Master of Arts

In the Program of

Immigration and Settlement Studies
\end{abstract}

Toronto, Ontario, Canada, 2014

(C) Casey Anderson 2014 


\section{DECLARATION FOR ELECTRONIC SUBMISSION OF A MAJOR RESEARCH PAPER}

(MRP)

I hereby declare that I am the sole author of this Major Research Paper. This is a true copy of the MRP, including any required final revisions, as accepted by my examiners.

I authorize Ryerson University to lend this MRP to other institutions or individuals for the purpose of scholarly research.

I further authorize Ryerson University to reproduce this MRP by photocopying or by other means, in total or in part, at the request of other institutions or individuals for the purpose of scholarly research.

I understand that my MRP may be made electronically available to the public.

Casey Anderson 


\title{
Proving it: Experiences of sexual minorities in the Canadian refugee determination system
}

\author{
Casey Anderson \\ Master of Arts 2014 \\ Immigration and Settlement Studies \\ Ryerson University
}

\begin{abstract}
This paper explores refugee claimant's experiences negotiating the Canadian Immigration and Refugee Board (IRB). Focusing on claims based on sexual orientation and gender identity, this paper investigates how claimants are made to 'prove' their sexual orientation and gender identity. The IRB and its decision makers require that claimants prove their identity as a refugee as well as a member of a sexual minority. Through an analysis of the existing literature and by integrating queer and feminist theoretical concepts on gender, sex, performativity and representation, it is apparent that the Canadian IRB functions as a heteronormative system in which the understanding of sexual orientation and gender identities are essentialized.
\end{abstract}

Key words:

sexual orientation; gender identity; refugee; heteronormative; Canada; sexual minority 


\section{Table of Contents}

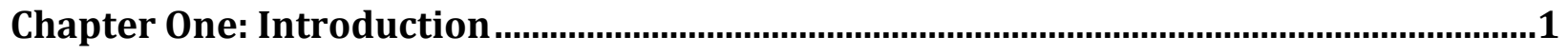

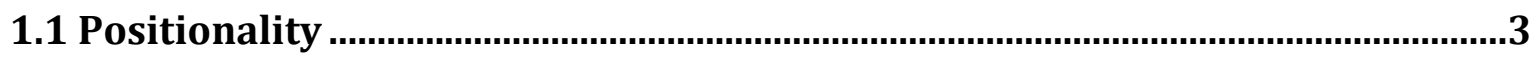

1.2 The power of language, labels and representation ..............................................4

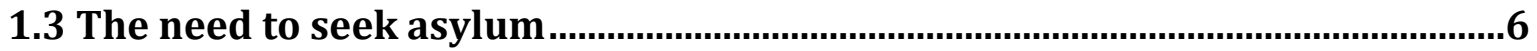

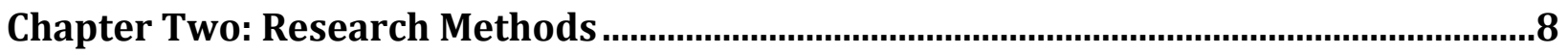

Chapter Three: A Review of the Current Literature ........................................................ 12

3.1 Canadian refugee policies..............................................................................12

3.2 Objective versus subjective evidence .............................................................15

3.3 Feminist and queer reading of SOGI claims.......................................................17

3.4 Bisexual refugee claims and "inconsistencies" ................................................... 24

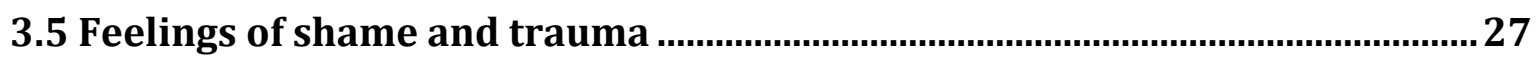

3.6 UNHCR guidelines and recommendations .........................................................28

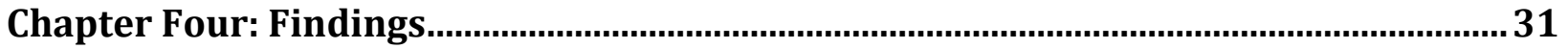

4.1 Overcoming the myth of repression to freedom...................................................31

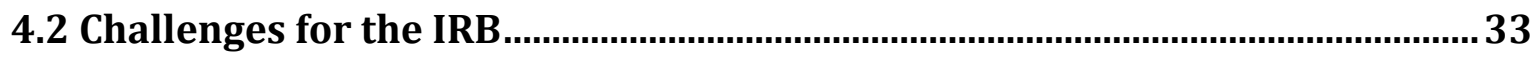

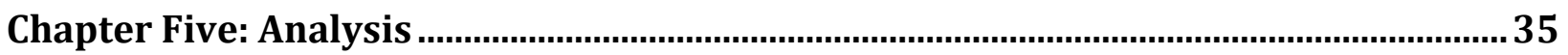

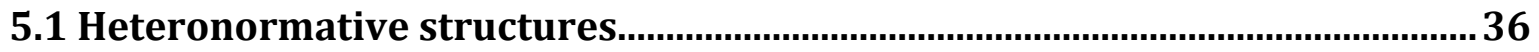

5.2 Essentialized (mis)understandings and the social construction of sexual

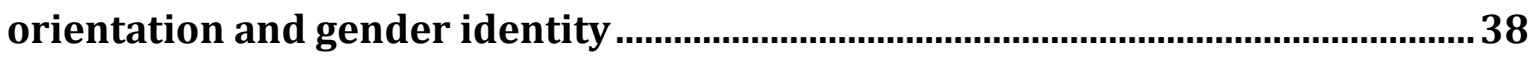

5.3 Labeling and representation ............................................................................ 41

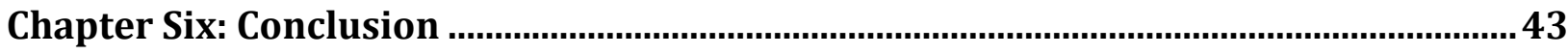

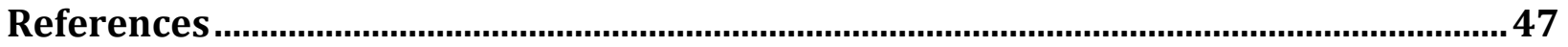




\section{Chapter One: Introduction}

The granting of asylum to select individuals-who must be few enough in number not to threaten dominant systems, but sufficient to lend credence to claims of first-world humanitarianism and democratic freedom-legitimizes exclusionary, repressive immigration control systems. The system thus positions queer asylum seekers in conflict with those seeking admission through the immigration system. (Luibhéid 2008, p. 180)

The manner in which individuals identify with, feel and express sexual orientation and gender identity is varied, personal and complex. Internationally, individuals face discrimination, violence and persecution due to their sexual orientation and gender identity. When governments are unwilling or unable to protect their citizens from such oppression, or they themselves are the source of oppression, individuals may leave their country of origin and seek asylum elsewhere. All claims in Canada are reviewed and processed according to the definition set out by the United Nations Convention Relating to the Status of Refugees (hereafter referred to as the Convention). Although the intention of the Convention's definition is to ensure global protection for individuals who have been failed by their own governments, the international application of the definition, particularly regarding claims based on individuals' Sexual Orientation and Gender Identity (SOGI), has been varied. Canada was one of the first nations to review and accept SOGI claims, yet the process itself is contentious. In Canada, refugee claims are reviewed and processed by the Immigration and Refugee Board (IRB) and its adjudicators. In order to be granted refugee status, individuals must document how they are distinguished as refugees according to the definition outlined by the Convention and upheld by the IRB. This paper will 
explore the ways in which SOGI claimants are not only required to validate their identities as refugees, but must also prove to the IRB that they are a 'sexual minority. ${ }^{1 \text {, }}$

As of 2008, Canada, Australia, France, Germany, New Zealand, Sweden, the United Kingdom, and the United States of America continue to review and accept SOGI claims (UNHCR 2008). SOGI claims represent a large and comparatively recent category of applicants and it appears as though there is still no answer for how to effectively and fairly assess such cases.

One of the main concerns of how to analyze and review SOGI claims is the question of how one's gender identity and sexual orientation is proven, and under what structures this is being done. Gender is a social construct that is understood by feminist and queer theorists as being fluid, flexible and varied (Butler 1990; Rehaag 2008a; Berg \& Millbank 2009; Ou Jin Lee \& Brotman 2011a). This paper will use a feminist and queer theoretical approach to examine the ways in which sexual orientation and gender identity is questioned and examined.

Sexual orientation and gender identity is neither static nor meant to fit into a singular mold (Butler 1990; Rehaag 2008a). The requirement that one must prove that they belong to a sexual minority assumes heterosexuality and that any deviation from that is something that requires proof: Heterosexual is the 'norm' and anything else is 'the other.' Although all refugee claims are challenging and rely on the qualification and experience of adjudicators to assess ones

1 The term sexual minority is used throughout this paper to refer to anyone who identifies as anything other than heterosexual. I also include in this definition any gender nonconforming, gender variant or transgender people. While I recognize the immense difference between these two definitions (that is, the difference between sexual identity and gender identity, not to mention the difference within these broad categories) for the purpose of this study it is important to understand that within the Canadian refugee system SOGI claims are understood to refer to people who are not-heterosexual, gender nonconforming, and therefore the term has merit. The complexities and challenges of labeling and categorization are further discussed in section 1.2 . 
validity according to their 'proof,' claims on the basis of one's sexual orientation are markedly

challenging due to the subjectivity and frequent lack of documentation or 'proof' (Jordan 2009). IRB adjudicators are responsible for ultimately deciding whether to 'accept' or deny ones sexual orientation and validate individual 'claims.' This raises questions about whether it is acceptable to ask for proof of 'difference.' And further, how does one prove such 'difference?' The subjectivity and the need for claimants to 'prove' their sexual orientation and gender identity essentializes identity characteristics and understandings. To prove difference one must demonstrate how 'out' or visible their sexual orientation is, something that is highly problematic.

\subsection{Positionality}

To speak about experiences of oppression from a position of privilege requires careful reflection and consideration. As a white, straight, Canadian woman engaged in a discourse on the experiences of SOGI claimants, I recognize the power and privilege that my position holds. I understand that because of my location I benefit from dominant systems of power. As a woman and a feminist I may also situate myself as a member of a society dominated by patriarchal structures that may assign my gender to that of an 'other.' However any 'differences' between my experiences and those of the claimants that this study explores does not mitigate my working within a supportive understanding of queer theory. As acknowledged by Sara Ahmed, "The differences between us necessitate the dialogue, rather than disallow it - a dialogue must take place, precisely because we do not speak the same language" (2002, p. 570).

As stated by Suzanna Danuta Walters, to come from such a position does not suggest that I may not pursue academics or discussions of this field, however it does mean that I must recognize and acknowledge my positionality. As a white, straight, woman, I come from a “structurally different place" (Walters 2005, p. 10). In recognizing this, I do not intend to speak 
for 'others,' but rather make space to consider the ways in which particular voices are made illegitimate. Ahmed emphasizes the need to speak "to each other, and of working for each other" (2002, p. 570). As stated by Ahmed, "proximity or distance" does not impede collectivity among 'us' and the 'other' (2002, p. 570). It is rather about how the collectivities are formed through the work that seeks to bring us together in spite of distance.

It is a 'we' that can be embraced only through a willingness to struggle with and for others who are faced in the present, a facing that is indebted to a past that cannot be left behind, as well as an openness to the future, as the promise and hope of what we might yet become. (Ahmed 2010, p. 570)

\subsection{The power of language, labels and representation}

The use of language regarding or referring to ones sexual orientation also necessitates careful consideration. In order to discuss a heterogeneous group of people based on their sexual orientation and gender identity I immediately recognize that I am creating a broad categorization of people. However, such categorization is necessary in this study and it must be acknowledged how labels are used and created to essentially discuss a group of people who do not identify as heterosexual. Existing label categories include 'lesbian,' 'gay,' bisexual,' 'transgendered,' 'transsexual,' 'intersexed,' 'queer,' 'two-spirit,' 'LGBTQ,' and other group or self-identified labels and categories. These words on their own refer to specific SOGI categories and are socially and culturally constructed, defined and understood. The meanings and implications behind these categories vary and some are more confining than others. The social understanding of a 'lesbian' is used to define or describe a woman who is sexually attracted to or romantically involved with other women. The term 'queer' is used with more fluidity and may be used to describe a person or group of persons who identify as non-heterosexual (I recognize this language and umbrella definition of non-heterosexual creates a problematic othering in itself). As the UNHCR definition explains, "Sexual orientation and gender identity are broad concepts 
which create space for self-identification" (UNHCR 2012, p. 2).

While I do not intend to reinforce problems associated with language categories, I have cautiously chosen to use the term sexual minority throughout this study. I recognize that language that is used to describe, define, label and categorize is problematic. Furthermore, I recognize the limitations and sensitivity of using restrictive language such as 'sexual minorities' to refer to a heterogeneous group. Additionally, the use of the word 'minorities' creates an 'othering' of individuals based on sexuality, and appears in contrast to the supposed norm of heterosexual. However, I apply the term in order to engage in an analysis of how this 'group' (whether real or socially constructed) is treated by the IRB.

Drawing on the work of Lionel Cantu (2009), I employ the idea that Western labels and categories of sexuality fail to account for the complexities of how sexual orientation and gender identities are understood and expressed (Ou Jin Lee \& Brotman 2011a). However, there is extensive evidence to merit the categorization of using 'sexual minorities' as a category in my own research focus. I acknowledge that in my own analysis I am limited by these existing identity categories and language. Much of the literature uses the term sexual minorities and provides qualitative research allowing participants who are themselves 'sexual minorities' to choose the language they prefer to identify with (Rehaag 2008; Ou Jin Lee \& Brotman 2011b). This classification, as noted by Ou Jin Lee and Brotman (2011a), includes a heterogeneous category of sexual identities that is not confined to the restrictive and often immutable categories of gay, lesbian or bisexual. Terms such as Lesbian, Gay, Bisexual, and Transgendered (LGBT) are restrictive and may assume homogeneity among heterogeneous populations. The classification of sexual minorities, as noted by Edward Ou Jin Lee and Shari Brotman (2011a), is less restrictive and allows fluidity and intersectionality of sexual identity categories, which is 
important to understand in a discussion and understanding of how SOGI claims are legally reviewed. As Sharalyn Jordan (2009) states, Western constructions understand sexual orientation and gender identity to be stable and categorically organized. The UN however denounces using such categories to review claims: "Not all applicants will self-identify with the LGBTI terminology and constructs as presented above or may be unaware of these labels" (UNHCR 2012, p. 5).

\subsection{The need to seek asylum}

Global occurrences of homophobia and transphobia are evident. While some nations legally state the protection of all individuals regardless of sex or gender, individual, social, cultural, political and religious structures that denounce non-heterosexual relations persist. In 2012 the UN released a document entitled the UNHCR Guidance note on refugee claims relating to sexual orientation and gender identity (hereafter referred to as the Guidance note). The document presents recommendations for legal grounds on how SOGI claims should be assessed. As stated by the Guidance note, "International and regional jurisprudence and legal doctrine affirm that discrimination on account of a person's sexual orientation is prohibited" (UNHCR 2008 , p. 7). In theory all humans should be viewed as equal under international rules of government as guided by UN law. However, in practice this is not the case; freedom of sexual orientation has not been legally accepted or socially understood as a fundamental international right (UNHCR 2008). In 2008 sexual minorities faced the potential death penalty in seven countries (LaViolette 2009) and as of 2012, seventy-eight countries criminalized same sex relations (Turk 2013). States' obligations to ensure the protection, safety and freedoms of all individuals regardless of their sexual orientation or gender identity is stated in international human rights laws in the UN Declaration of Human Rights, the UN Convention, the Universal 
Declaration of Human Rights, the International Covenant on Civil and Political Rights, and the Committee against Torture (UNHCR 2013). Although Article 1 of the Universal Declaration of Human Rights states that "all human beings are born free and equal in dignity and rights, " it appears that this has not been upheld (UNHCHR 2011, p. 4).

Settlement services are an important aspect of refugee settlement, support and engagement in Canada. Based on my knowledge and experiences working within the settlement service sector, it became evident that services directed towards the specific needs of sexual minorities was lacking. I wanted to conduct a study that explored these particular experiences in order to better identify and understand the needs of sexual minority refugees in Canada. This paper will provide a thorough analysis of the current literature and qualitative studies pertaining to SOGI refugee claims in Canada and analyze the ways in which claimants are subjected to bureaucratic structures that essentialize one's sexual orientation and gender identity. 


\section{Chapter Two: Research Methods}

My research methods were chosen with a number of factors in mind. Initially I had envisioned a study in which I would interview former refugee claimants in Toronto about their experiences negotiating the IRB, focusing on the notion of having to prove their sexual orientation and gender identity. Using a grounded theory analysis of qualitative research, I wanted to pair this with the literature on SOGI claims in order to compare and further explore such experiences. What proved difficult, and ultimately made me rethink this process, were both the sensitive nature of SOGI claims as well as the limited scope of a Major Research Paper. As I conducted a literature review of SOGI claims it became clear to me that even before speaking with claimants there was much to write about in terms of the existing literature. That is, an analysis of the literature, and process, seemed necessary before engaging with people who had gone through it. I subsequently decided to change my research methods from a qualitative analysis using interviews, to an analysis of the refugee process through a feminist and queer theoretical lens. To do this, I merged a practical review of the process with feminist and queer literature in order to critique the seemingly heteronormative structures of the IRB. Focusing on a secondary analysis of SOGI literature, I was able to closely and critically review the lived experiences of claimants.

Because I did not conduct qualitative research or speak with SOGI claimants first hand, there are certain limitations to my study. The study is based on the research of other scholars, creating limitations as a result of using secondary sources. Because I did not conduct direct interviews, I rely on the available research and publications of others. Interviews were conducted in various settings, at different time periods, and with different interview structures and questions. These factors may have attributed to varying outcomes and may have influenced a 
participant's answers. However, this does not negate the importance of this study. The quality of the available research is high and the themes and topics explored allow the scope of my research to cover a large sample size and time period and allows for a valuable study which has allowed me to distill important and recurring themes. Furthermore, the application of a queer and feminist theoretical perspective that is central to this study, allows for an important critical analysis into the structures of the refugee process in Canada and complexities of SOGI claims. Furthermore, I do not intend to speak for the claimants, the scholars or the IRB. Rather, my intentions are to draw attention to the issues associated with SOGI claims, and an analysis of the current literature allows me to effective explore these topics.

Much of the published literature on the topic of SOGI claims has been through an examination of claimant's experiences within the IRB, focusing on how applicants negotiate and manage decision maker's expectations. Sexual minorities face global discrimination and persecution on account of their sexual orientation or gender identity that is the basis of SOGI claims. Discrimination may be physical or psychological including arbitrary detention, sexual assault, physical abuse, murder, torture, police brutality, barriers to accessing healthcare, education, housing, employment and other social services, denial of legal rights, as well as social stigma (UNHCHR 2011; International Commission of Jurists 2010).

In a search of the current literature pertaining to sexual minority refugees in Canada, the Ryerson University Library and Archives online database, JSTOR, Toronto Public Library database, and Google Scholar, were used to conduct an initial search. The key words used in the search were "sexual minority," "refugees" and "Canada." The term "sexual minority" was further substituted with "queer," "gay,” "lesbian," "LGBT(Q)," "homosexual," "transgendered," "SOGI," and "bisexual." All databases retrieved similar results and the language variation did 
not significantly change the search outcome. The literature is primarily presented as a presentation and analysis of primary qualitative studies. Notable studies that will be reviewed are the works of Edward Ou Jin Lee, Shari Brotman, Sharalyn Jordan, Nicole LaViolette, Sean Rehaag, and Jenni Millbank.

Due to the relatively recent nature of SOGI claims being processed in Canada, there have been significant amendments and clarification in the IRB, which affect the way such claims are reviewed. For this reason, it is useful to review the most recent literature available. Most of the research has been conducted and published within the past ten years.

All refugee claims are reviewed within established legal structures that are used to guide and set precedence for all legal decisions. In order to best understand international refugee law, part of this paper reviews UNHCR policies and recommendations. To understand the Canadian legal interpretation of UNHCR policies, as well as national laws, I reviewed Citizenship and Immigration Canada and the Immigration and Refugee Board of Canada documents.

Due to the vast differentiation in global refugee determination systems in law and in practice, this study will focus specifically on the Canadian refugee system. Without intention to limit the research to the same geographical constraints, the literature for review has been exclusively from an English language perspective. I presume this is due to a variety of factors, namely that in nations where sexual minority refugees originate there are social and legal constraints that make it difficult, if not impossible, to publish literature on the topic of sexual minorities. I do recognize that I am limited to English and English translated texts, which may further account for these limitations. However, as stated by Ou Jin Lee and Brotman, "focusing only on Canadian legal scholarship limits our capacity to understand additional dimensions related to how sexual minority refugees interact with the Canadian refugee regime" (2011a, p. 
262). Although the current literature provides a valuable and in-depth knowledge base, an exclusively English language and Canadian voice to a struggle that affects refugee claimants who originate from non-English and non-Canadian States is demonstrative of a knowledge gap in the literature. 


\section{Chapter Three: A Review of the Current Literature}

Propelled by fear of violence and flight from stigma, impelled by desire for connection and belonging, the movements of people whose sexualities or genders defy and offend norms cover a complex spatial, social, and psychological terrain. (Jordan 2009, p. 165)

\subsection{Canadian refugee policies}

To begin an analysis of the current literature it is important to first understand Canadian refugee policies and amendments since SOGI claims were first accepted in 1991. Canada's Immigration and Refugee Protection Act accepts the United Nations definition of a refugee as:

A person who, by reason of a well-founded fear of persecution for reasons of race, religion, nationality, membership in a particular social group or political opinion, is outside each of their countries of nationality and is unable or, by reason of that fear, unwilling to avail themselves of the protection of each of those countries. (Rehaag 2008a, p. 64)

Although this broad definition fails to explicitly address sexual orientation or gender identity as a means for seeking refuge, the inclusion of SOGI claimants was clarified in the 1993 case of Canada (Attorney General) v. Ward. In this landmark decision by Justice La Forest, the inclusion of sexual minority refugees was established and the interpretation of what it means to be a member of a 'particular social group' was legally defined (Rehaag 2008a, p. 68). The Supreme Court of Canada designates that members of a particular social group are:

1. Groups defined by an innate or unchangeable characteristic; 2 . groups whose members voluntarily associate for reasons so fundamental to their human dignity that they should not be forced to forsake the association; and 3. groups associated by a former voluntary status, unalterable due to its historical permanence. (IRB 2013).

SOGI claims have been understood by the Supreme Court to be classified as members of a particular social group by stating; "The first category would embrace individuals fearing persecution on such bases as gender, linguistic background and sexual orientation" (IRB 2013).

This definition categorically labels that members of a sexual minority group are defined by 
'innate' or 'unchangeable characteristics.' Although this legal clarification has opened up Canada's borders to SOGI claimants, the interpretation of sexual orientation as "immutable" is limiting as it fails to recognize that sexuality may be fluid and flexible, changing and developing over time (Berg \& Millbank 2009; Ou Jin Lee \& Brotman 2011a; Rehaag 2008a).

In her analysis on the Canadian IRB, Nicole LaViolette references the case of Re X.(J.K.) which dates back to 1993. In this case a Polish gay man made a claim for asylum in Canada on the basis of his sexual orientation. Under initial review it was determined that his claim did not fall under the category of a 'social group' because as a gay man he was deemed to be a member of an 'asocial' group. This interpretation was made based on Article 16(3) of the Universal Declaration on Human Rights which references the family as "the natural and fundamental group unit of society and is entitled to protection by society and the state" (LaViolette 1997, p. 18). In $\operatorname{Re} X .(J . K$.$) decision makers understood that heterosexuals were the "family" and therefore$ represented the unit that was entitled to protection, and so it was understood that the gay man seeking asylum was 'asocial' (LaViolette 1997). Although this decision was contested, it is representative of the heteronormative structure of the Canadian IRB in 1993 when the definition of membership in a social group was established.

Although the Canadian IRB has outlined the meaning of a social group, it was not until a 2002 Global Consultation when the UNHCR defined how 'membership in a particular social group' was to be understood:

A group of persons who share a common characteristic other than their risk of being persecuted, or who are perceived as a group by society. The characteristic will often be one which is innate, unchangeable, or which is otherwise fundamental to identity, conscience, or the exercise of one's human rights. (Buscher 2011, P.4)

This UNHCR definition contains similar restrictions to that of the IRB designation, reiterating 
the language of this characteristic as 'unchangeable' and 'innate.'

As of December 2012, there are several ways in which individuals may claim asylum in Canada: outside Canada, at the port of entry or after arrival in Canada at an immigration office (CIC 2012a). As outlined by the IRB, all claimants are required to complete a Basis of Claim Form (BCF) outlining the reason(s) for seeking protection. The BCF is used as the primary documentation for seeking protection in Canada and if the initial claim is not rejected it will be referred to the IRB. A hearing by the Refugee Protection Division (RPD) will follow in which claimants must narrate their reasons for seeking refuge and must prove the authenticity of their claim. SOGI claims are narrated in a manner to express and document experiences as a sexual minority in their country of origin and demonstrate how this attributes to a "well-founded fear of persecution" (Rehaag 2008, p. 64). In this regard individuals must prove the authenticity of their claim to the IRB. The task to prove persecution as well as the authenticity of sexual orientation or gender identity, and the need for IRB adjudicators to evaluate this, presents a number of complexities. The requirement that individuals fit within a limiting definition further complicates the expectation that claimants 'prove' themselves.

As is defined by the UNHCR, sexual orientation is understood to be "a person's capacity for profound emotional, affectional and sexual attraction to, and intimate and sexual relations with, individuals of a different gender or the same gender, or more than one gender" (UNHCR 2008, p. 5). The UNHCR has further defined gender identity as “each person's deeply felt internal and individual experience of gender, which may or may not correspond with the sex assigned at birth" (UNHCR 2008, p. 5). The UNHCR's use of the term 'sexual minorities' refers to ones' sexual orientation and gender identity. 


\subsection{Objective versus subjective evidence}

In all refugee claims subjective evidence in the form of personal narratives is used, however this is particularly prevalent in cases based on sexual orientation (Berg \& Millbank 2009, p. 196). In the case of sexual minorities, claims rely heavily on personal accounts and often lack proof beyond individual narratives (Millbank 2009; UNHCR 2008). These personal and private encounters are exposed and challenged throughout the claims process (Berg \& Millbank 2009) and when proof is not reasonably available, personal testimony is heavily weighted (UNHCR 2008). According to the UNHCR Handbook on Procedures and Criteria for Determining Refugee Status (hereafter referred to as the Handbook), "if the applicant's account appears credible, he [or she] should unless there are good reasons to the contrary, be given the benefit of the doubt" (UNHCR 2008, p. 16). The Handbook outlines that "benefit of doubt" should be considered, acknowledging that it is not always possible for claimants to provide evidence (Millbank 2009; UNHCR 2008). Although the Guidance is clear on the stance for how to account for the lack of objective evidence, the use of "benefit of doubt" has not always been upheld. "LGBT refugees risk having their claim denied if they are not able to speak openly about their sexual identity, how they were treated in their home countries based on that identity, and how it led to their flight" (Buscher 2011, p. 96).

Laurie Berg and Jenni Millbank (2009) demonstrate the IRB's favouring of 'objective' evidence to assess claims. This evidence, in the form of legal documentation and proof of persecution, is a challenge for all parties involved, as SOGI claimants often do not have access to such reports (Berg \& Millbank 2009). Information regarding international abuses that sexual minorities face may not have been documented for certain States, or in cases where information is available it may be outdated (LaViolette 2009). LaViolette notes that the IRB historically 
favours international reports from governments and credited international organizations such as Amnesty International. Generally information gathered by independent sources that may offer valuable and necessary information have been ignored or dismissed as not credible (LaViolette 2009). In recent years there has been increased collaboration between all levels of organizations, which has contributed to more accessible and accredited sources of persecution that applicants may present in their claims process (LaViolette 2009). However, as LaViolette (2009) points out, there continue to be States in which reports are not available. International reports are useful for IRB members to better understand the potential persecution and discrimination that SOGI claimants face in their countries of origin.

There are numerous reasons as to why it is difficult, if not impossible, to have access to evidence. Ou Jin Lee and Brotman (2011a) further indicate that in States where sexual minorities are criminalized, acts of violence or discrimination are not reported and therefore statistics are not available or are grossly inaccurate. The inaccuracy of evidence is also due to generalized societal discrimination that leads to the fear that if sexual minorities report a crime they fear further discrimination or persecution will result (Ou Jin Lee \& Brotman 2011a). Furthermore, gender based violence is often not reported since victims may fear or distrust authority figures, or there may not even be a system set up to report it (UNHCHR 2011). If an individual has experienced violence based on an act that is criminalized, they may in turn be labeled as the criminal.

When authority figures themselves are the source or definitive cause of persecution, such acts go undocumented. A 2011 study commissioned by the UN High Commissioner for Human Rights (UNHCHR) which sought to understand international discriminatory laws and practices based on sexual orientation and gender identity reported that in Jamaica, violence on the basis of 
sexual orientation and gender identity is evident. In one instance a man was murdered (allegedly) after the police encouraged others to beat him up. It was also stated that the police not only instigated but also participated in the physical violence that led to the man's killing (UNHCHR 2011). When authority figures do not protect or are themselves the source of oppression, it is difficult if not impossible to obtain documentation or 'proof' of abuse (UNHCHR 2011; Ou Jin Lee \& Brotman 2011a).

The Guidance note states that laws which prohibit 'homosexual' activity, whether directly or indirectly, such as a law against "carnal acts against the order of nature," impede individuals' human rights and therefore present a valuable case for an asylum claim (UNHCR 2008, p. 10). Laws that infringe on ones' rights are demonstrative of societal intolerance of ones' identity (UNHCR 2008, p. 11).

\subsection{Feminist and queer reading of SOGI claims}

Although the legal interpretation and understanding of sexual orientation has been understood to be immutable, a queer and feminist theoretical lens understands sexual orientation and gender identity as fluid (Ou Jin Lee \& Brotman 2011a; Rehaag 2008a; Berg \& Millbank 2009). Refuting the classification of sexual orientation and gender identity is central to the critical review of the IRB presented by Ou Jin Lee and Brotman (2011), Rehaag (2008), Berg and Millbank (2009). The authors challenge the notion that there is a single categorization or labeling of how sexual minorities identify with, feel, or experience life. It is important to understand these complexities and to not generalize populations, as well as to understand that sex and gender have been socially constructed in Canada according to Western ideals where the existence of a "universal gay identity" may be assumed which in effect limits individuals" experiences and expressions of sexual orientation and gender identity (Ou Jin Lee \& Brotman 
2011). Judith Butler (1990), Sara Ahmed (2002) and Eve Kosofsky Sedgwick (1993) offer

important contributions to how gender and sex are understood through a queer and feminist lens.

In her book Gender Trouble (1990), and her following article “Critically Queer" (1993), Butler discusses the concept of gender performativity. Butler defines performative acts as the compulsory expectations and understanding of gender and gender roles that are carried out and created by heteronormative powers and structures (Butler 1993, p. 19).

Gender is performative insofar as it is the effect of a regulatory regime of gender differences in which genders are divided and hierarchized under constraint. Social constraints, taboos, prohibitions, threats of punishment operate in the ritualized repetition of norms, and this repetition constitutes the temporalized scene of gender construction and destabilization. There is no subject who precedes or enacts this repetition of norms. (Butler 1993, p. 22)

The last sentence is imperative to understand; that subjects are created after the norms are stylized and repeated, not before. It is important to understand that performative acts of gender are not voluntary; they are not an act or performance that people choose to portray or switch on or off, rather they are "compulsory" and expected (Butler 1993, p. 26). Ahmed's discussion of heteronormativity provides an important understanding of how societal structures are created and 'normalized' for those who 'fit' in: "Heteronormativity functions as a form of public comfort by allowing bodies to extend into spaces that have already taken their shape" (Ahmed 2002, p. 425).

It is important to understand the language and concepts embedded in sex and gender as they are varied and often debated. Sex is defined as being directly linked to the physical body, based on physiology and organs: man and woman. The assumption is that biological sex establishes your sexual preference as being the 'opposite' (Sedgwick 1993, p. 8). Gender is often conflated with sex, which is strongly rejected by feminist thinkers. Gender is commonly thought about in binary terms of masculine and feminine; a man has masculine traits and a woman has feminine traits. These binaries, along with heterosexuality, are understood to be the norm (Butler 
1993, p. 23). Gender and sex have been constructed in a manner which assumes they are inextricably linked and out of this understanding gender roles that have been prescribed have often been understood as being natural or 'normal.' This notion is firmly rejected by Butler, Ahmed and Sedgwick who state that there is nothing natural about the behavioural characteristics and traits that are linked to the male and female body, rather it is taught: "Gender is the repeated stylization of the body, a set of repeated acts within a highly rigid regulatory frame that congeal over time to produce the appearance of substantive, of a natural sort of being" (Butler 1990, p. 45). Because gender is constructed and shaped by societies and cultures, the construct of gender itself may change over time, space and place (Butler 1990; LaViolette 2007).

As stated by Butler, "The category of sex is the political category that founds society as heterosexual" (Butler 1990, p. 1). Sex has become politicized to take on certain meanings that are not natural nor ascribed, rather they are created and understood and this politicization has been used to create and understand a society that is in itself heterosexual. The way we think of sex, man and woman, is the basis in which we see the world as heterosexual; one thinks of men as naturally interested in women and vice versa. Monique Wittig further suggests that the language of "sex" has been constructed within a framework that assumes heterosexuality as the norm (Butler 1990, p. 36). The understanding of gender as a social construct is critical to understanding an analysis of the IRB and how the expression of gender and sexual orientation is understood.

Judith Butler (1990) further provides an important feminist theoretical approach to understanding the ways in which individuals are represented. In her analysis of language, Butler (1990) questions how language categories may lead to misrepresentation or no representation of peoples and communities, outlining the problems that arise through politicized categorizations, 
such as 'women,' and the problems that arise when a single category is assumed to be representative of a "common identity." The notion of representation and who is included is an important theme that is relevant to an analysis of the Canadian refugee process and how sexual minorities have been represented and how this effects and perhaps hinders the possibility of having claimants 'prove' themselves. A 'representation' of what a sexual minority is has been created by social and cultural (mis)understandings, stereotypes and generalizations. "The domains of political and linguistic 'representation' set out in advance the criterion by which subjects themselves are formed, with the result that representation is extended only to what can be acknowledged as a subject" (Butler 1990, p. 2). Butler (1990) considers the consequences of how women have been represented: on the one hand, representation of women has created "visibility" and "legitimacy" to a group that was otherwise invisible. On the other hand, representation has also allowed for assumptions and perceptions of what is normal (Butler 1990, p. 2). It is important to explore the way in which people are represented and how these representations are used to legitimize and understand identity by essentializing. Although the representation of the 'gay' community has been successful in creating agency, voice and legitimacy, it has also been essentialized and minimized by the representation of what it means to be 'gay.'

The IRB's understanding of sexual orientation and gender identity greatly differs from that which is understood by feminist and queer thinkers. The IRB's limited interpretation of the Convention's definition of SOGI refugees is contentious. The manner is which sexual minorities have been legally categorized and understood to be immutable shapes the way that refugee claimants present their case within the IRB and the manner in which the IRB receives these claims (Rehaag 2008). They must further 'prove' that they are a sexual minority in accordance 
with the IRBs' understanding of sexuality as 'immutable.' SOGI claimants must narrate their identity to a Board Member who may not understand possibilities of fluidity and non-conforming notions of sexual orientation and gender identity. As stated by Edward Ou Jin Lee and Shari Brotman, "When sexual and gender identity can be framed by an IRB adjudicator as an immutable personal characteristic, this leaves little room for sexual minority refugees to articulate their own definitions of sexual or gender identity" (2011a, p. 265).

A queer theoretical interpretation rejects the understanding of sexual orientation and gender identity that is prevalent in the Canadian refugee determination system. Queer migration theory is an interdisciplinary approach that considers race, ethnicity, gender, class, geography, and citizenship status and recognizes the non linear patterns and forms of sexual identity categories that change with location and time (Luibhéid 2008, p. 170). "Queer is a continuing moment, movement, motive-recurrent, eddying, troubling" (Prosser 1998, p. 32) To state that sexuality is immutable, as the IRB assumes, is representative of an essentialist understanding of sexuality (Rehaag 2008a): "Essentialists hold that individuals easily fall into categories such as gay and straight, based either on biological or early-childhood psychological factors" (Rehaag 2008a, p. 80). The Canadian IRB's lack of understanding and acceptance of anything beyond an immutable notion of sexuality assumes the need for protection on account of ones inability to choose their sexual orientation. Rehaag (2008a) refers to this as the IRB's "immutability defense" (p. 90).

Rehaag (2008a) explores the notion of the "immutability defense" in his valuable study of how bisexual claims are reviewed. Rehaag suggests that within this defense, sexuality is understood to not be a choice, and the notion of innate or immutable is central to the claim. The reasoning behind this notion is that, because sexual orientation or gender identity is not chosen, it 
requires protection. The underlying debate here is that if someone 'chooses' their sexuality they can 'choose' to be heterosexual. Rehaag asks, if one chooses to accept this, where do bisexuals fit in the classification of innate and immutable? (Rehaag 2008a). This question is central to Rehaag's study. In a queer and feminist analysis flexibility and fluidity are central to the understanding of sexuality and sexual orientation, something the IRB has failed to consider (Rehaag 2008a; Ou Jin Lee \& Brotman 2011a).

In 2012 the UN released a publication entitled UNHCR Guidelines on International Protection (hereafter referred to as the Guidelines) outlining recommendations on how to conduct legal proceedings for SOGI claimants. The report emphasized the need to move away from a fixed understanding of sexual orientation and gender identity, particularly when based on stereotypes: "Different people realize at different points in their lives that they are LGBTI and their sexual and gender expressions may vary with age, and other social and cultural determinants" (UNHCR 2012, p.3).

There are varied accounts of claimants' experiences negotiating the IRB with a SOGI claim documenting problematic experiences which result from legal pressure to conform to a Western social construct and understanding of sexual orientation and gender identity. All refugee claims are processed through an oral hearing in which individuals must present their case to an IRB adjudicator who is ultimately responsible for deciding their fate in Canada (CIC 2012b). In order to prepare for a hearing, claimants often seek legal advice from a lawyer receiving information and guidance on how to successfully present their case. There are a number of qualitative reports (Jordan 2009; Namaste et al. 2011) outlining the advice and guidance that claimants received from lawyers; instances of lawyers recommending that claimants 'perform' certain gender roles, change their physical appearance, and wear different clothes to appear more 
'effeminate' or 'butch.' This 'legal' advice may be seen as a reflection of lawyers' knowledge, understanding and previous experience negotiating the IRB.

In her records of qualitative research, Jordan cites an interview with a lesbian South American woman who demonstrated her awareness of how decision makers would potentially review her claim; "I knew I had to look as butch as possible to be sure I looked like a lesbian to the judge. So I pulled back my hair, no make up. Put my baseball cap on sideways, and picked my most classic white shirt. I made sure I sat with my shoulders square and feet planted wide" (2009, p. 173).

The encouragement and advice for individuals to conform to heteronormative structures and Western social constructions of SOGI claims is provided so that claimants will more effectively be able to 'prove' themselves as a member of a sexual minority. In a study conducted by Viviane Namaste, Sean Rehaag and Tamara Vukov (2011), one claimant stated that her lawyer advised her to cut her hair short in order to present more 'masculine,' as a means to successfully be identified and categorized as a lesbian. The assumption then, is that the IRB's understanding of a lesbian is that they are women who present masculine qualities. A woman's femininity is understood to be an indicator of the heterosexual 'norm.' The association is that a masculine woman is a lesbian and a feminine woman is heterosexual. Similarly, an effeminate man is perceived to be gay and a masculine man heterosexual. There is a search for or expectation of men being 'effeminate' and women being 'masculine.' The purpose of the lawyer's advice on how to present is to have a successful claim and to convince adjudicators of the authenticity of their sexual orientation or gender identity. In these examples we see that how to present an 'authentic' SOGI claim is to perform according to socially constructed and understood norms. Through a presentation of her own qualitative research, Jordan looks into how 
expectations of refugees are managed and equated to the perceived and not the authentic identity. "All queer claimants are working with and against culturally proscribed identity narratives in their hearings" (Jordan 2009, p. 176).

\subsection{Bisexual refugee claims and "inconsistencies"}

Sexual minority claims seem to challenge decision makers and this is particularly evident for bisexual claims. For sexual minority claimants to fit into an understanding of sexuality as immutable is particularly difficult, as fluidity is at the root of their sexual orientation. Bisexuals are perceived as being engaged in both 'homosexual' and 'heterosexual' relationships, often discussed as two distinct elements and expressions of sexuality, rather than recognizing fluidity. Claims on the basis of bisexual status demonstrate a further challenge to the IRB's heteronormative understanding of sexuality by the so-called 'inconsistencies' of identity (Rehaag 2008a). Resulting from these structural barriers, bisexuals have a lower success rate in relation to other SOGI applications (Rehaag 2008b). There appears to be a difficulty among decisionmakers to understand the truthfulness of a claim because of histories or current status of 'heterosexual' relationships. Bisexual refugee claimants have proven to be the "other other" of sexual minority claimants (Dicks 2007) and represent the "invisible otherness" (Ou Jin Lee \& Brotman 2011a, p. 263).

Rehaag (2008b) seeks to understand the variation in acceptance rates for bisexuals in comparison to the average of all refugee claims as well as sexual minority claims. Rehaag aligns himself within a queer theoretical framework while analyzing refugee law in Canada, while reviewing the decisions of 160 cases between 2001-2004. Rehaag's (2008b) study is important not only in demonstrating the disadvantages that bisexuals face, but also as an account of the bigger picture of how SOGI claims are reviewed. Rehaag effectively demonstrates that bisexual 
claims have a lower acceptance rate because their sexual orientation is viewed as inconsistent, and therefore not credible. Inconsistencies do not fit in with decision makers understanding. It goes against the mold of how an individual's sexual orientation and gender identity is understood. This is reflective of a larger picture in which stories that do not match perception are written off, rejected, or dismissed. Inconsistencies in this manner are often deemed as not credible (Rehaag 2008a). Rehaag cites a telling example of men who were deemed to be not credible after they expressed they were not familiar with the 'gay scene' in Canada.

Namaste et al. (2011) reviewed Canadian IRB decisions of bisexual claimants between 2004 and 2007, analyzing adjudicators' reasons for rejecting claims. The study concludes that when bisexual claimants spoke about their 'heterosexual' experiences, the IRB questioned the authenticity of the claim as a sexual minority. In a sense bisexual claimants must demonstrate that they are more 'homosexual' than 'heterosexual:' "The claimant [has not] established his identity as a bi-sexual person. There is evidence that he is heterosexual... The claimant testified he has not had any homosexual relationships in Canada" (Namaste et al. 2011). When bisexual claimants have had previous heterosexual marriages or have children, this is further perceived to be evidence of the inauthenticity of their claim (Namaste et al. 2011). Decision makers have suggested that bisexual claimants have 'heterosexual privilege' that they may take advantage of (Namaste et al. 2011). This is highly problematic and suggests that bisexuals must fit into a heterosexual world, and anything that challenges this is not welcome. It suggests that a claimant should conceal their identity in the public realm, which is confining and also suggests that relationships are limited to the private realm and sexual acts (Namaste et al. 2011). As stated by one IRB member, "Bisexuality is perceived as something that can be hidden through heterosexual relationships. Within this logic, involvement with an opposite-sex partner is 
evidence that bisexual applicants will not face risks because they will not be visible to agents of persecution" (Namaste et al. 2011). One adjudicator suggested that a male bisexual claimant go back to his wife and children: "If his wife accepts him back" (Namaste et al. 2011). This is representative of the IRB managing how individuals live their lives. Bisexual claimants appear to have difficulty proving the honest nature and fluidity of their relationships.

In Namaste et al's study, it was revealed that in some cases IRB adjudicators indicated that they questioned bisexual claimants who were involved in heterosexual relationships in Canada on the basis that Canada is a 'free' country (2011). Adjudicators wondered why the claimant would not take advantage of this newfound sexual freedom (Namaste et al. 2011). In this regard the authenticity of their claim is being questioned based on the expression of sex and relations in Canada. It ignores many complexities and is embedded with assumptions. It also fails to understand that claimants have a history of trauma related to expressions of sexual orientation and gender identity and those feelings of shame, trauma and depression do not go away once in Canada (Millbank 2009, p. 27). Individuals may be accustomed to discreet and hidden relations, and so it is challenging to move beyond that (Jordan, 2009). Luibhéid notes that the belief that homophobia and discrimination does not exist in Canada, and in the refugee determination process, is reflective of colonialist ideals. Luibhéid indicates that refugee migration is not a move from oppression to freedom, but rather an experience of "restructured inequalities and opportunities through migration" (Luibhéid 2008, p. 170). Ahmed (2002) discusses the restrictive notion of suggesting that people conceal homosexual acts in a way that is in keeping with allowing heterosexuals to feel comfortable. 


\subsection{Feelings of shame and trauma}

Berg and Millbank (2009) and Ou Jin Lee and Brotman (2011a) document the feelings of shame, depression, and retraumatization that claimants experience through having to prove their case and identity. During oral hearings, applicants must provide reasons for seeking asylum and provide detailed information about their experiences and fears of persecution. At every step of making a claim applicants must retell stories that may be difficult to express. Having to retell stories of trauma may result in feelings of shame, depression, and retraumatization (Berg \& Millbank 2009; Ou Jin Lee \& Brotman 2011a). Furthermore, to talk openly about sexual orientation and gender identity is likely a new experience for SOGI claimants who may have led a discreet life regarding their sexual orientation or gender identity or may just be beginning to process their sexual identity (Berg \& Millbank 2009). In a study that was published in 2002, 75 percent of SOGI claimants in the United Kingdom indicated that the first time they had spoken about their experiences of trauma and persecution was after arriving in the UK or during refugee hearings (Berg \& Millbank 2009). Within the IRB the experience of openly discussing SOGI claims is in a sense an experience of having to "come out" again and repeatedly (Ou Jin Lee \& Brotman 2011a). The force of having someone ratify their sexuality, which they have been told in their country of origin is wrong, unnatural or a criminal act, may lead to more feelings of shame and trauma (Millbank 2009) and reminders of violent experiences of first 'coming out' or a realization of a one's gender identity and sexual orientation (Ou Jin Lee \& Brotman 2011a ). Butler (1990) and Ahmed (2002) discuss the possible feelings of shame that arise when one does not conform, or follow the 'script,' of going against the 'norm' and therefore is engaged in a state of difference. This has various implications on the claimant's ability and desire to openly discuss these sensitive issues with decision makers. 
Berg and Millbank (2009) state an important consideration regarding trauma. It is not just issues of retraumatization that make it difficult, if not impossible, for claimants to openly and clearly discuss their experiences of persecution, but in reality they may not remember it. When people experience traumatic events their recollection may be hindered by memory loss, posttraumatic stress disorder and depression (Berg \& Millbank 2009). "Stress, shame, depression and trauma, as well as the passage of time, negatively affect the ability to recall" (Wessels 2011, p. 40). When claimants experience memory loss they may present incomplete or inconsistent accounts of persecution in their country of origin (Berg \& Millbank 2009). When documentation of persecution, whether written or oral, is inconsistent, these are immediate indicators of possible inauthenticity of a claim (Berg \& Millbank 2009). Retraumatization negatively affects the ability to clearly and openly communicate stories to the IRB in a need to 'prove' oneself. Retraumatization may also be prompted by the stress of having to 'prove' oneself: "Perhaps more so than any other type of claim, SOGI claimants are being asked to recount events steeped in shame that are intertwined with a stigmatized identity" (Jordan 2009, p. 178).

\subsection{UNHCR guidelines and recommendations}

Central to Jordan's (2009) study is the notion that international migration has a tendency to assume all migrants as heterosexual. The assumption is highly problematic and is the root of this critique and analysis of the current structure and workings of the Canadian IRB. Resulting from this dangerous and limiting assumption, legal systems have been structured in a way that is set up for heterosexuals. The Canadian IRB seemingly portrays a representation of these heteronormative structures that assume heterosexuality as the norm and any deviation from this demands a need to 'prove' this 'difference.' “Articulating a place for queer migrants entails 
exploring the complex interrelationships of queer sexualities and genders with migration" (Jordan 2009, p. 167).

The 2008 UNHCR Guidance Note, published under the Protection Policy and Legal Advice Section and Division of International Protection Services, is an important document pertaining to the rights and recommendations of how SOGI claims should be reviewed and determined. As stated in the Guidance, "Through analyzing international legal principles, jurisprudence and other relevant materials, these Guidance Notes seek to clarify applicable law and legal standards with the aim of providing guidance in the particular thematic area concerned" (UNHCR 2008, p. 2).

LaViolette highlights the significance of the UNHCR's 2008 Guidance as it is the first publication which explicitly addresses and provides recommendations on how States should deal with cases (LaViolette 2009). This document may be used to advocate for the rights of SOGI claims, and understandings that sexual minorities face particular discrimination.

It is important to note that the Guidance clearly rejects the idea that individuals should be discreet or conceal their sexual orientation and gender identity. Namaste et al. demonstrate that this has been suggested by some adjudicators who stated that claimants be "discreet in their homosexual relationships" (2011 p. 16). The Guidance Note emphasizes that it is not acceptable to ask or expect claimants to live discreetly as a protective solution: "A proper analysis as to whether a LGBTI applicant is a refugee under the 1951 Convention needs to start from the premise that applicants are entitled to live in society as who they are and need not hide that" (UNHCR 2012, p. 5). It is not acceptable to ask or expect an individual to hide their sexual orientation or use 'heterosexual privilege' in the case of bisexuals (UNHCR 2008, p. 12). Claimants are not expected to put forth an inauthentic identity to avoid persecution (UNHCR 
2008, p. 12). Although the UNHCR states that case law does not allow for adjudicators to suggest claimants keep their sexual orientation private or hidden, in the case of bisexual claimants this has not been upheld (Namaste et al. 2011). As stated by the Canadian IRB "A hidden right is not a right" (UNHCR 2008, p. 13). 


\section{Chapter Four: Findings}

As affirmed by the literature and the 2012 Guidelines, societal understandings of 'normal' gendered roles and behaviours are often understood according to heteronormative ideals. It is further apparent that the Canadian IRB is demonstrative of a system that operates under a heteronormative structure. When claimants whose sexual orientation and gender identity deviate from a heteronarrative, they must negotiate and manage a system that is searching for 'difference' and for individuals to fit into a singular mold. "Heteronormativity functions as a form of public comfort by allowing bodies to extend into spaces that have already taken their shape" (Ahmed 2002, p. 425). Under such normative or heteronormative structures the mold has been created and all are expected to fit in. SOGI claimants must 'prove' their difference as a 'minority' and how they differ from heterosexuals, while simultaneously fitting into a heteronormative narrative and understanding of what a sexual minority 'is.' The literature largely examines how the IRB assesses sexual minority claims and essentially requires claimants to "prove" their sexual identity. As succinctly noted by Ou Jin Lee and Brotman, the refugee determination system in Canada "organizes the lives and disorganizes the psyches of sexual minority refugees" (2011a p. 242). When claimants recount personal stories, they are often assessed according to the adjudicator's understanding of sexuality, which has been largely formed by societal constructions. Adjudicators are essentially looking for claimants' stories to match their own perceptions (Berg \& Millbank 2009a).

\subsection{Overcoming the myth of repression to freedom}

The Guidelines (2012) recognize that many SOGI claimants will not have 'come out' in their country of origin. They may be making a claim not on the basis of persecution that they 
have experienced, but rather on the claim that they have a well-founded fear of persecution or as a sur place claim. Resulting from feelings of shame and discrimination, many claimants will not immediately state the sexual orientation and gender identity as the primary reason for seeking asylum (Buscher 2011). There is an assumption that once in Canada, claimants are free and therefore able to be open and expressive of their sexual orientation and gender identity. Laws that seek to manage and criminalize sexual acts and relationships have been deemed to violate individuals' rights to privacy (UNHCHR 2011, p. 6). The ways in which same-sex relations are managed are discriminatory and separate heterosexual practices from those deemed 'others.' In 2011, the UNHCHR's 2011 report stated that fourteen States have different consent ages for heterosexual and same-sex relations. The existence of rules and regulations defies many international agreements, yet it persists:

Many states and societies impose gender and sexual orientation norms on individuals through custom, law and violence and seek to control how they experience personal relationships and how they identify themselves. The policing of sexuality remains a major force behind continuing gender-based violence and gender inequality. (Onufer Corrêa et al. 2007, p. 6).

Canada is perceived as being a nation of freedom, offering acceptance and space for people who have been discriminated against in their 'repressed' States. This is understood to be the myth of moving from 'repression' to 'freedom.' Although discrimination based on sex and gender in Canada is criminalized, and the rights of all individuals are protected, discrimination persists. The repression to freedom model assumes that SOGI claimants have faced oppression in their country of origin and that upon arrival in Canada they will openly assert their sexual identity through public relationships, sexual behaviour and involvement in the 'gay community.' The belief of repression to freedom held by decision makers impacts their understanding of how SOGI claimants should live their lives once in Canada. 
Individuals often experience an intersectionality of factors that leave them in a further position of oppression. People may be discriminated against on account of their sexual orientation or gender identity as well as their race, religion, ethnicity, health problems, and country of origin (UNHCR 2012). Intersectionality may be the cause of not 'coming out' and 'coming out' may be the source of further discrimination. Jordan cites one case in which the applicant stated that he had not openly 'come-out' in Canada because he was a member of a church group and his religious affiliations were a source of conflict (Jordan 2009). This is also representative of an apparent rejection of the narrative of repression to freedom. Jordan (2009) further states that claimants also expressed feelings of 'alienation' in Canada. There is a great deal of intersectionality of oppression for sexual minority claimants which further hinders their access to a successful claim and permanent settlement in Canada.

Adil stated that in his country of origin (Gulf state) he did not know or associate with other gay people because of fear he would isolate himself from other individuals, communities and associations (Jordan 2009). "So I was always quiet. Keeping myself in — to survive. Dress in a certain way so I won't attract attention. Even walk in a certain way because I don't want attention" (Jordan 2009, p. 170).

\subsection{Challenges for the IRB}

Reviewing claims based on sexual minority status has proven to be a great challenge for the IRB. On the one hand it is important that the IRB not accept false claims in order that they not put the refugee determination system at risk. On the other hand it is important that adjudicators do not deny legitimate claims that send claimants back to a situation of harm, or refoulement, which is illegal under the provisions of the UNHCR Convention and Protocol Relating to the Status of Refugees (UNHCR 2008). 
When federal laws have been established to denounce and criminalize sexual activity and manage what is the perceived norm in a relationship, this effectively 'allows' discrimination, persecution and stigma against sexual minorities (Jordan 2009). A culture of non-acceptance is effectively created and supported by the legal application of establishing 'norms.'

SOGI claims have been reviewed since the early 1990s and the way in which they have been assessed and interpreted has changed through various policy amendments. Along with policy changes the social construction of sexual orientation and gender identity has shifted. As articulated by Butler and LaViolette, because gender is socially constructed, the concept and understanding of gender may change over time, space and place (Butler 1990; LaViolette 2007). It is important to note and understand the possible advancements and shifts in how SOGI claims are understood and reviewed within the IRB. Because these changes have occurred over time, the time period in which studies are conducted is important to consider. Studies that were conducted in the early 1990s when claims were initially reviewed greatly vary from those conducted in the 2000s. Though problems of reviewing SOGI cases remain, it is important to note that advancements have been made.

SOGI claimants' navigation of the IRB becomes highly complex and has the potential for devastating consequences that are highlighted throughout the literature. As is apparent from a secondary data analysis of the current literature and existing qualitative analyses, the idea of proving oneself has become an important and necessary aspect of Canadian IRB cases pertaining to SOGI claims. 


\section{Chapter Five: Analysis}

Undertaking an asylum application entails accessing and working within a refugee system that was not designed with LGBTQ refugees in mind; requiring claimants to document an often hidden and stigmatized identity, and to disclose experiences, some traumatic, that are deeply private. In refugee hearings or interviews, applicants work with/against Western narratives of $L G B T$ identities and coming out for recognition of their 'membership in a particular social group, ' while their credibility is scrutinized. (Jordan 2009, p. 166)

Concentrating on the works of Edward Ou Jin Lee, Shari Brotman, Sean Rehaag, Sharalyn Jordan, Laurie Berg, and Jenni Millbank, this chapter will identify and explore the key concepts and themes that were raised in the literature through a queer and feminist theoretical lens. The findings in this chapter focus on the above mentioned authors who have conducted secondary data analyses and qualitative studies that primarily focus on interviews with SOGI claimants who have gone through the refugee claims process in Canada.

In order to conduct a thorough analysis of the readings, articles were grouped together based on methodology, chronology, and prevalent themes. The articles by Ou Jin Lee, Brotman, Rehaag, Jordan, Berg, and Millbank, were all published after 2008, representing the most recent studies. Ou Jin Lee and Brotman's article (2011a) focuses on community based qualitative research that was conducted between 2008 and 2010, focusing on identity, refugeeness and belonging among SOGI refugees in Canada. While incorporating a queer theoretical analysis, Rehaag (2008) successfully contributes to what he identifies as a gap in the existing literature by focusing on the stories and experiences of bisexual claimants. In his study he thoroughly reviews and cites past decisions made by the IRB regarding SOGI claims. Jordan's (2009) qualitative research provides the findings of interviews with SOGI claimants and refugees as well as settlement service providers and lawyers. Offering an important literary analysis, Berg and Millbank's (2009) publication focuses on how decision maker's constructions of sexual 
orientation and gender identity influence how decisions are made. Berg and Millbank review past decisions and transcripts that provide important insight on the topic.

After conducting a literature review, the article findings were synthesized by making note of and further exploring relevant and recurring topics that were consistent among all of the literature. The main themes that were extracted from the literature were heteronormative structures, essentialized understandings of sexual orientation and gender identity, and labeling. These themes are further explored in this chapter. Drawing on feminist and queer theory readings by Butler, Sedgwick and Ahmed, concepts of social construction, representation and performativity were further explored and connected to the themes synthesized from the literature review.

\subsection{Heteronormative structures}

The most profound theme that is recurring throughout the literature is that the Canadian IRB functions as a heteronormative system. Heteronormative systems are structured in ways that assume heterosexual relationships, behaviours, and 'norms.' When heterosexuality is the norm, any deviation from this must be 'proved' and articulated to decision makers. When SOGI claimants are required to 'prove' their sexual orientation or gender identity within heteronormative structures they are confined. As stated by Eithne Luibheid,

Most scholarship, policymaking, service provision, activism, and cultural work remain organized around the premise that migrants are heterosexuals (or on their way to becoming so) and queers are citizens (even though second-class ones). Where do queer migrants figure in these frameworks and activities?" (Jordan 2009, p. 167).

It is evident from a review of claims that queer migrants, or refugees, do not fit into the frameworks and activities that are structured by the IRB in Canada. Rather, sexual minority refugees must restructure their behaviour and identity markers and traits to 'fit' into such 
heteronormative structures. As stated by Ahmed, "Normativity is comfortable for those who can inhabit it" (2002, p. 425). Those who fit outside the boundaries of 'normal' are rejected and unaccounted for. They are asked to prove how they fit into a normalized or 'heteronormative' structure. As demonstrated by Rehaag (2008a), this appears to be most evident in the case of bisexual refugee claimants who must prove that they are 'more' homosexual than heterosexual. In line with negotiating a heteronormative system, is the notion of performative gender roles. As discussed, in the literature review, performativity refers to the compulsory gender roles that are ascribed through social constructs and understanding that men present 'masculine' traits and women present 'feminine traits'. Central to Butler's discussion is the power that is embedded in the discourse of performativity. Butler (1993) argues that as a society we must be conscious of the ways in which such identity categories are created: "Freedom, possibility, agency do not have an abstract or pre-social status, but are always negotiated within a matrix of power" (Butler 1993, p. 22). It is interesting to note claimants' own understanding of sexual orientation and gender identity according to their knowledge of Western constructions and assumptions and how this affects their understanding of themselves and how they 'should' express these aspects of their identity. As documented by Jordan (2009), in an IRB interview, a claimant stated that a search on the Internet about gay men led to his understanding that gay men were "muscular" and "manly." This led the claimant to question his own identity as a gay man compared to his newfound understanding of what to be gay is. He questioned his own gender identity, thinking if being gay was to be manly and masculine, where did he fit in? What is gay? (Jordan 2009, p. 170).

Under heteronormative structures, performative gender roles are ascribed to be normalized and strict. The result of understanding heterosexuality as the norm is that systems of 
decision making and review are constructed under heteronormative systems in which deviation from expectations is unwelcome and deemed not credible. When claimants are advise by lawyers to ascribe to certain gender roles this puts claimants in a position to decide if they are willing to take on a gendered role which may not be representative of who they are. The moral complications of deciding whether to 'conform' or not may lead to a rejected claim and authentic claims may be compromised as a result: "Alana is engaged in a struggle to make herself recognizable to the judge as a "member of the particular social group"-lesbian" (Jordan 2009, p. 174). The 'repercussions' of not confining to such stereotypes and construction may be dangerous. "Having fled persecution, queer refugee claimants' potential for safety and belonging is constrained when they do not conform to conventions" (Jordan 2009, p. 166).

\subsection{Essentialized (mis)understandings and the social construction of sexual orientation and gender identity}

A further theme of exploration is the essentialized understanding of sexual orientation and gender identity that is evident within the IRB. When sexual orientation and gender identity is essentialized, the understanding of what a sexual minority is becomes based on a limited understanding that simplifies the complexities. Decision makers are looking for claimants to look, act, speak, and behave a certain way. This is linked to the concepts of representation and the social construction of sexual orientation and gender identity that Butler explores.

Adjudicators are essentially looking for claimants' stories to match their own perceptions (Berg \& Millbank 2009). This is representative of decision makers folk knowledge which is knowledge based on cultural understandings of 'common sense' (Ou Jin Lee \& Brotman 2011). These constructions of sexuality influence how they make decisions. "Rigid notions of homosexual identity may consciously or subconsciously shape decision-makers' approaches in 
this field" (Berg \& Millbank 2009, p. 195).

In several cases presented by Rehaag (2008), decision makers are cited as suggesting that they did not believe that the claimant was at risk of being persecuted because they did not 'look gay' or did not 'display' gay 'behaviour.' Decision makers stated that they did not believe that the man suffered abuse because "he does not openly display [being gay]" (Rehaag, 2008a, p. 72). It is evident that in the IRB claimants are expected to match decision makers' expectations of what a sexual minority is according to assumptions based on their physical appearance, traits and characteristics. Namaste et al. refer to an IRB adjudicator's opinion on one SOGI case that "The claimant's apparel or demeanour does not reveal any sexual preference” (Namaste et al. 2011). As Millbank (2009) notes, adjudicators are influenced by a claimant's demeanor, such as physical appearance, consistency and plausibility.

There is a false understanding that a universalized gay identity exists. This is an important theme to explore and is related to how gender and sexual orientation is constructed. The socially constructed understanding of what it is to 'be gay' is varied. These constructions are based on culture, religion, politics, and representations. Along with rejecting a universalized gay identity, one must understand that there is no single understanding of what makes a person 'gay' or how this is expressed (LaViolette 1997). Furthermore, the intersectionality of oppression that is faced, on account of being a sexual minority refugee is important to consider.

The term 'double marginality' has been coined to highlight how the effect of being both LGBT and a refugee is not simply the cumulative sum of belonging to both groups but rather that these marginalizations are compounded, yielding profound distancing from traditional support systems and resources." (Buscher 2011, p. 97)

As stated by Berg and Millbank, "It is important to note at the outset that staged models of sexual identity development were derived from a Western experience and perspective, which 
may not be applicable to other cultural contexts" (2009, p. 207). Ou Jin Lee and Brotman (2011a) cite the limitations of Western labels of sexuality and sexual construction which minimize the complexities of sexual expression.

Sexual minority refugees are forced to account for their experiences through the lens of Western conceptualizations of sexual and gender identity, both as defined within Canadian refugee law and as interpreted by Immigration and Refugee Board (IRB) adjudicators. (Ou Jin Lee \& Brotman 2011a, p. 153)

Stereotypes and adjudicators' own social understanding further influence decisions. The way in which individuals identify with gender may vary and rarely fits into binary categories of male and female. That is to say not all men are 'masculine.' What happens when a woman is 'masculine?' When people do not neatly fit into binaries of men and women they are seen as deviating from the norm. A queer theoretical understanding of sexuality rejects the notion that people have one true sexual orientation that is static (Rehaag, 2008a). "Rigid notions of homosexual identity may consciously or subconsciously shape decision-makers' approaches in this field" (Berg and Millbank, 2009, p. 195).

The IRB's model of understanding sexual orientation and gender identity as essentialized is problematic. There is an assumption that individuals are straight until proven otherwise. This is highly contentious and a shift is needed to move away from having claimants prove themselves. The Guidance note states that sexual minority claimants "do not need to document activities in the country of origin indicating their different (sic) sexual orientation or gender identity" (UNHCR 2008, p. 16). Essential to the literature is the notion that individuals are assumed to be straight and any deviation from this is a perceived other. Embedded in this assumption is the expectation that people 'explain' or defend the reasons as to why they chose to engage in certain relationships: "The claimant could not adequately explain why he was toying 
with her and a possible serious relationship. He could not explain why he spoke about marriage with her, given his homosexual interests. It does not make sense" (Namaste et al. 2011). This is evidence of the assumption that individuals are 'straight until proven otherwise' and heterosexuality is the socially constructed norm.

\subsection{Labeling and representation}

Creating gender 'norms' is formed through the power of labeling. In her example Butler refers to the seemingly innocent yet profound nature of compulsory performative acts that is embedded at birth with the statement "It's a girl!" (Butler 1993, p. 23). This is a clear demonstration of how gender is not voluntary, it is not a conscious choice, rather it is derived out of repetitive acts that 'normalize' and essentialize the meaning and compulsory expectations of gender (Butler 1993; Ahmed 2002). As stated by Berg and Millbank, "In the refugee context, it is always the decision-maker and not the applicant who has the power to name, the authority to decide who the applicant 'really' is and what sexuality 'really' means” (Berg \& Millbank 2009, p. 208).

SOGI claimants who did not want to label or categorize themselves were found to be at a disadvantage. In his study Rehaag (2008a) describes the story of a woman who was questioned about how she identifies as a lesbian. She resisted the label "lesbian," because for her this was not at the root of her identity. Rather, this label was imposed on her. It is important to allow people to speak for themselves and choose how or if they identify themselves within such categories. The structures that SOGI claimants are forced to work within are defined by heteronormative language, labels and categories.

There is a consensus in the literature that the heteronormative and essentialist framework

of the refugee system in Canada must be reformed. Individuals must not be labeled and expected 
to perform and represent certain gender roles. Gender is socially constructed and will vary. The expectation of what a SOGI claimant is, is confining and does not allow for individual stories to be shared and reviewed as the individual cases they are.

Individuals face discrimination and persecution on account of their perceived sexual orientation and gender identity (International Commission of Jurists 2010; UNHCHR 2011). Whether lesbian, straight, or bisexual, when individuals are labeled as such they are immediately identified as an 'other' based on perception. When people do not fit an understanding of socially or culturally constructed norms they fall outside what is understood to be the norm. A critical analysis and review of the current literature indicates that the Canadian IRB is a bureaucracy that dangerously subjects SOGI claimants to a narrative of what a sexual minority is based on socially constructed understandings of sexual orientation and gender identity. As stated by Jordan, "While seeking refugee protection, queer refugees are evaluated against expected narratives of refugee flight and of LGBT identity" (2009, p. 165). 


\section{Chapter Six: Conclusion}

Assessing the veracity of the claimant's sexual orientation or gender identity is a very difficult, sensitive and complex task in the context of an administrative or quasi-judicial hearing. In particular, the very private and intimate nature of an individual's sexual orientation or gender identity poses real challenges for adjudicators, who are nonetheless required to examine the claimants' personal lives and relationships. (LaViolette 2009, p. 441)

The intention of this study is to contribute to and expand on the existing literature and to draw attention to the problems of how heteronormative systems place individuals at a disadvantage by requiring that they 'prove' something that is not meant to be nor can be proved. This study is intended to be a compilation and analysis of published literature to communicate the experiences of sexual minority refugees as they negotiate the IRB, in order to shine light on the complexity of the process and the ways in which the IRB may be improved to respect the heterogeneous experiences of refugee claimants.

After understanding the ways in which the IRB functions, it is clear that decision makers involved in the refugee selection process must look for alternative understandings of sexual orientation and reject the notion that sexual minorities must fit into a mold of a one size fits all model. The IRB must stop focusing on one's expression and presentation of sexual orientation and gender identity, and rather listen to the narrative of discrimination and persecution that is being expressed.

If we follow feminist and queer theoretical understandings of sex and gender we can better understand and identify the problems that are embedded in the IRB structures and the need to 'prove' oneself. Within the IRB, labels and categories are often imposed on claimants, which is reflective of the power dynamic of the adjudicator who labels, and the refugee who is labeled (Berg \& Millbank 2009; Lacroix 2004; Ou Jin Lee \& Brotman 2011a). Aligning with feminist and queer thought will improve the experiences of both sexual minority claimants and those who 
hear their claims. "In such acts of alignment (rather than merger), we can re-shape the very bodily form of the community, as a community that is yet to come, as a community that is without ground, and yet not ungrounded" (Ahmed 2002, p. 570).

It is important to remember that there are many individuals around the world who struggle with persecution, discrimination and violence because of their sexual orientation and gender identity who may not have the financial means or information available to seek asylum. Particularly in States where same-sex relations are criminalized, individuals may not be aware of how to make a claim for asylum. Such instances require assistance from international bodies, such as the UNHCR to provide direct assistance within the nation state (UNHCR 2012).

It is apparent from reviewing the literature that refugee claims on the basis of sexual orientation are some of the most difficult cases for adjudicators to review (Jordan 2009). As stated by Berg and Millbank, "We found a common refrain in case law that 'allegations' of gay identity are easy to make and hard to disprove" (2009, p. 196). Although the Canadian tribunal has yet to successfully assess claims removed from subjectivity and adjudicators own concepts of sex and gender, the consensus of the literature is that improvements have been made in Canada, particularly in comparison to other nations that accept SOGI claims. However, discrimination persists and there is a need for further research as well as policy recommendations for how to improve the effectiveness of the refugee determination process and improve the experiences for sexual minority claimants.

It is neither possible nor acceptable to expect an individual to demonstrate their sexual orientation and gender identity, particularly within a legal structure that appears to understand a restricted definition of what it is to be a 'sexual minority.' Rehaag (2008) suggest that a move towards a fundamental dignity approach would be the most effective solution to how SOGI 
claims are reviewed in Canada. Central to this approach is the way in which it seeks to assist all individuals whose "associations challenge heteronormativity" (Rehaag 2008, p. 99).

Under [the fundamental-dignity] approach, IRB members, instead of asking whether a person is truly a member of a particular sexual minority, simply need to determine whether a person is likely to associate-or to be perceived as associating-with others in a manner that challenges the inevitability or desirability of exclusive heterosexuality. As a result, rather than mandating the suspect exercise of assessing refugee claimants' "true" or "authentic" sexual identities, the fundamental-dignity approach directs IRB members to inquire into alleged human-rights violations that are aimed at compelling claimants to forsake associations in the name of heterosexuality. (Rehaag 2008, p. 99)

We need to work towards an understanding of sexual orientation and gender identity that does not essentialize, but rather allows people to feel, express and identify as they wish. What needs to be judged by a decision maker is not how 'gay' people look, act or seem, but how much they are in need of protection. The focus must shift away from an approach which views individuals as subjects who need to prove their validity; rather they need to be assessed for their fear of persecution and the human rights violations which they face.

It is important to reject these social constructions and understand sexuality as fluid rather than immutable (Ou Jin Lee \& Brotman 2011; Rehaag 2008; Berg \& Millbank 2009). Individual experiences and expressions of sexual orientation and gender identity change over time, and can be difficult to 'prove' in any concrete way. In this regard it is especially important not to draw generalizations about a heterogeneous population.

This study only captures the surface of how SOGI refugees navigate and negotiate migration and settlement. Settlement is a process that is not completed with a refugee hearing or an accepted claim (Jordan 2009). The appropriate provision and application of settlement services in Canada is very important to continue to support and speak up against the global atrocities that continue to allow individuals to be persecuted and discriminated against due to 
their sexuality and gender identity. As a society we must continue to fight for global rights and norms to challenge this widespread discrimination. Human rights must apply to all and fundamental rights must be established and upheld on a global level. As emphasized by the UN High Commissioner for Human Rights, "The principle of universality admits no exception. Human rights truly are the birthright of all human beings" (International Commission of Jurists 2010, p. 4).

Western concepts of sexuality must not be universalized as the IRB has done in their application of a universal "gay" identity (Lacroix 2004; Ou Jin Lee \& Brotman 2011a). The perception of sexual identity as either linear or universal must be rejected in order to move away from the heteronormative framework of the refugee determination process. Rather than requiring claimants to restructure who they are to fit into normative structures, the system must be restructured to account for the reality of difference and identity that exists. 


\section{References}

Ahmed, S. (2002). This other and other others. Economy and Society, 31(4), 558-572

Bach, J. (2013). Assessing transgender asylum claims. Forced Migration Review, 42, 34- 42.

Berg, L. \& Millbank, J. (2009). Constructing the Personal Narratives of Lesbian, Gay and Bisexual Asylum Claimants. Journal of Refugee Studies, 22(2), 195-223.

Breen, D. (Nov. 7, 2012). UNHCR issues new guidelines on claims to refugee status based on sexual orientation and gender identity. Human Rights First. Retrieved from http://www.humanrightsfirst.org/2012/11/07/unhcr-issues-new-guidelines-on-claimsto-refugee-status-based-on-sexual-orientation-and-gender-identity/

Buscher, D. (2011). Unequal in Exile: Gender equality, sexual identity and refugee status. Legal Perspectives on Gender and Sexual Equality. 3(2) 92-102.

Butler, J. (1990). Gender Trouble. UK: Routledge.

Butler, J. (1993). Critically Queer in The Routledge Queer Studies Reader. (2013). Hall, D. and Jagose, A. (Eds.). pp. 18-31

(CIC 2012a) Citizenship and Immigration Canada. (2012). Resettlement from outside Canada. Retrieved from http://www.cic.gc.ca/english/refugees/outside/index.asp

(CIC 2012b) Citizenship and Immigration Canada. (2012). Determine your eligibility- Refugee status from inside Canada Retrieved from http://www.cic.gc.ca/english/refugees/inside/apply-who.asp

Dicks, S. (2007). Interpreting the other other: assessing refugee claims based on sexual orientation in an anti-refugee climate. These and Dissertations. Ryerson University. Paper 467. pp. 1-75.

(IRB 2013) Immigration and Refugee Board of Canada (2013). Chapter 4: Grounds of Persecution. Government of Canada. Retrieved from http://www.irb-cisr.gc.ca/Eng/BoaCom/references/LegJur/Pages/RefDef04.aspx

International Commission of Jurists (April 2010). Sexual Orientation and Gender Identity in Human Rights Law. pp. 1-165. Retrieved from http://www.refworld.org/docid/4c627bd82.html [accessed 6 September 2013]

Jordan, S. (2009). Un/Convention(al) Refugees: Contextualizing the Accounts of Refugees Facing Homophobic or Transphobic Persecution. Refuge, 26(2), 165-182. 
Jordan, S. and Morrissey, C. (2013). "On What Grounds" LGBT Asylum Claims in Canada. Forced Migration Review, 42, 13-15.

Lacroix, M. (2004). Canadian refugee Policy and the Social Construction of the Refugee Claimant Subjectivity: Understanding Refugeeness. Journal of Refugee Studies, 17(2), 147-166.

LaViolette, N. (2009). Independent Human Rights Documentation and Sexual Minorities: an ongoing challenge for the Canadian refugee determination process. The International Journal of Human Rights, 13(2-3), 437-476.

LaViolette, N. \& Whitworth, S. (1994). No Safe Haven: Sexuality as a Universal Human Right and Gay and Lesbian Activism in International Politics. Journal of International Studies, 23(3) 563-588.

Luibhéid, E. (2008). An Unruly Body of Scholarship. GLQ: A Journal of Lesbian and Gay Studies, 14(2-3), 169-183.

Millbank, J. (2009). 'The Ring of Truth': A Case Study of Credibility Assessment in Particular Social Group Refugee Determinations. International Journal of Refugee Law. 21(1), 1-33.

Namaste, V., Rehaag, S., \& Vukov, T. (2011). Sexual minority refugee determinations in Canada: The experience of bisexual claimants. Slides 1-21.

Ou Jin Lee, E. \& Brotman, S. (2011a). Identity, Refugeeness, Belonging: Experiences of Sexual Minority Refugees in Canada. Canadian Review of Sociology. 48(3), 241-274.

Ou Jin Lee, E. \& Brotman, S. (2011b). Exploring Gender and Sexuality through the Lens of Intersectionality. Canadian Social Work Review. 28(1), 151-156.

Prosser, J. (1998). Judith Butler: Queer Feminism, Transgender, and the Transubstantiation of Sex in The Routledge Queer Studies Reader. (2013). Hall, D. and Jagose, A. (Eds.). pp. $32-59$.

Rehaag, S. (2008a). Patrolling the Borders of Sexual Orientation: Bisexual Refugee Claims in Canada. McGill Law Journal. 53. pp. 59-102. Retrieved from http://www.heinonline.org.ezproxy.lib.ryerson.ca/HOL/Page?page=59\&handle $=\mathrm{h}$ ein.journals\%2Fmcgil53\&collection=journals

Rehaag, S. (2008b). Troubling Patterns in Canadian Refugee Adjudication. Ottawa Law Review. 39(2). pp. 337-362. Retrieved from http://yorkspace.library.yorku.ca/jspui/bitstream/10315/9958/1/Rehaag-TroublingPatterns.pdf 
Sedgwick, E. (1993). Queer and Now in The Routledge Queer Studies Reader. (2013). Hall, D. and Jagose, A. (Eds.). pp. 3-17.

Shildo, A. and Ahola, J. (2013). Mental Health Challenges of LGBT Forced Migrants. Forced Migration Review. 42, 9-11.

Turk, V. (2013). Ensuring Protection for LGBTI Persons of Concern. Forced Migration Review. $42,5-8$.

(UNHCR 2008) United Nations High Commissioner for Refugees. (21 November 2008). UNHCR Guidance Note on Refugee Claims Relating to Sexual Orientation and Gender Identity. pp. 1-18. Retrieved from http://www.unhcr.org/refworld/pdfid/48abd5660.pdf

(UNHCR 2012) United Nations High Commissioner for Refugees. (2012). Guidelines on International Protection no. 9. pp. 1-17. Retrieved from http://www.unhcr.org/509136ca9.pdf

(UNHCR 2013) United Nations High Commissioner for Refugees. (2013). Sexual Orientation and Gender Identity. Retrieved from http://www.refworld.org/sogi.html

(UNHCHR 2011) United Nations High Commissioner for Human Rights (17 Nov 2011). Discriminatory laws and practices and acts of violence against individuals based on their sexual orientation and gender identity. pp. 1-85. Retrieved from http://www2.ohchr.org/english/bodies/hrcouncil/docs/19session/A.HRC.19.41_English.p df

Walters, S. (2005) From Here to Queer: Radical Feminism, Postmodernism, and the Lesbian Menace in Queer Theory. Morland, I. and Willox, A. (2005). pp. 6-21. Palgrove MacMillan, NY.

Wessels, J. (2011). Sexual orientation in Refugee Status Determination. Refugee Studies Centre, University of Oxford. Working Paper Series No. 73, 1-58. 